\title{
Engineering bone regeneration with novel cell-laden hydrogel microfiber-injectable calcium phosphate scaffold
}

\author{
Yang Song ${ }^{1,3 *}$, Chi Zhang ${ }^{2,3 *}$, Ping Wang ${ }^{3}$, Lin Wang ${ }^{3,4}$, Chunyun Bao ${ }^{2,3}$, \\ Michael D. Weir ${ }^{3}$, Mark A. Reynolds ${ }^{3}$, Ren Ke ${ }^{5}$, Liang Zhao ${ }^{3,6}$, Hockin H. K. Xu ${ }^{2,7,8}$ \\ ${ }^{1}$ Department of Prosthodontics, Guanghua School of Stomatology, Guangdong Provincial \\ Key Laboratory of Stomatology, Sun Yat-sen University, Guangzhou, Guangdong, China \\ ${ }^{2}$ State Key Laboratory of Oral Diseases, West China Hospital of Stomatology, Sichuan \\ University, Chengdu, Sichuan 610041, China \\ ${ }^{3}$ Department of Endodontics, Periodontics and Prosthodontics, University of Maryland \\ School of Dentistry, Baltimore, MD 21201, USA \\ ${ }^{4}$ VIP Integrated Department, School and Hospital of Stomatology, Jilin University, \\ Changchun, Jilin 130011, China \\ ${ }^{5}$ Department of Neural and Pain Sciences, School of Dentistry, \& Program in Neuroscience, \\ University of Maryland, Baltimore, MD 21201, USA \\ ${ }^{6}$ Department of Orthopaedic Surgery, Nanfang Hospital, Southern Medical University, \\ Guangzhou, Guangdong 510515, China \\ ${ }^{7}$ Center for Stem Cell Biology and Regenerative Medicine, University of Maryland School of \\ Medicine, Baltimore, MD 21201, USA \\ ${ }^{8}$ University of Maryland Marlene and Stewart Greenebaum Cancer Center, University of \\ Maryland School of Medicine, Baltimore, MD 21201, USA
}

For: Materials Science \& Engineering C-Materials for Biological Applications 1st Revision, submitted in Feb. 2017

Correspondence: Dr. Ping Wang, University of Maryland School of Dentistry, Baltimore, MD 21201, email: dentistping@gmail.com; Dr. Liang Zhao, Department of Orthopedic Surgery, Southern Medical University, Guangzhou, Guangdong 510515, China, email: lzhaonf@126.com; Dr. Hockin H. K. Xu, Director of Biomaterials \& Tissue Engineering Division, Department of Endodontics, Periodontics and Prosthodontics, University of Maryland Dental School, Baltimore, MD 21201, USA (Email: hxu@ umaryland.edu).

* The first two authors contributed equally.

Short title: Bone regeneration with injectable CPC-cell-microfibers

Keywords: bone tissue engineering; calcium phosphate cement; mesenchymal stem cells; cell-encapsulating microfibers; injectable paste; animal studies. 


\section{Abstract}

Cell-based tissue engineering is promising to create living functional tissues for bone regeneration. The implanted cells should be evenly distributed in the scaffold, be fast-released to the defect and maintain high viability in order to actively participate in the regenerative process. Herein, we report an injectable calcium phosphate cement (CPC) scaffold containing cell-encapsulating hydrogel microfibers with desirable degradability that could deliver cells in a timely manner and maintain cell viability. Microfibers were synthesized using partially-oxidized alginate with various concentrations $(0-0.8 \%)$ of fibrinogen to optimize the degradation rate of the alginate-fibrin microfibers (Alg-Fb MF). A fibrin concentration of $0.4 \%$ in $\mathrm{Alg}-\mathrm{Fb} \mathrm{MF}$ resulted in the greatest enhancement of cell migration, release and proliferation. Interestingly, a significant amount of cell-cell contact along the long-axis of the microfibers was established in Alg- $0.4 \% \mathrm{Fb} \mathrm{MF}$ as early as day 2. The injectable tissue engineered construct for bone reconstruct was fabricated by mixing the fast-degradable Alg- $0.4 \% \mathrm{Fb} \mathrm{MF}$ with $\mathrm{CPC}$ paste at $1: 1$ volume ratio. In vitro study showed that cells re-collected from the construct maintained good viability and osteogenic potentials. In vivo study demonstrated that the hBMSC-encapsulated $\mathrm{CPC}-\mathrm{MF}$ tissue engineered construct displayed a robust capacity for bone regeneration. At 12 weeks after implantation, osseous bridge in the rat mandibular defect was observed in CPC-MF-hBMSCs group with a new bone area fraction of $(42.1 \pm 7.8) \%$ in the defects, which was more than 3 -fold that of the control group. The novel tissue-engineered construct presents an excellent prospect for a wide range of dental, craniofacial and orthopedic applications. 


\section{Introduction}

With an aging population and numerous sports- and traffic-related injuries, there is an increasing need for bone repair and regeneration. In particularly, bone defects with limited intrinsic regenerative potential represent a considerable surgical challenge. Cell-based tissue engineering approaches are highly promising to address this issue through the construct of a scaffold with living cells, with the aim to generate a cell-driven, functional tissue rather than to fill the defect with a nonliving scaffold [1-3]. An effective tissue-engineered construct should act both as a scaffold to bridge the defect and as a cell delivery vehicle to distribute cells throughout the scaffold to promote tissue regeneration $[1,4,5]$.

Calcium phosphate cement (CPC), first developed in 1986 and approved in 1996 by the Food and Drug Administration (FDA) for craniofacial defect repairs, is one of the promising bone substitutes with excellent bioactivity, biocompatibility and osteo-conductivity [6, 7]. An aqueous paste can be injected into the osseous defects and set in situ during surgery, which can be resorbed and replaced by new bone in vivo [6-12]. A major challenge is how to efficiently deliver live cells in the CPC scaffold with the aim to boost bone regeneration. The cell delivery system critically affects cell viability, growth and differentiation, and thus plays a decisive role for the subsequent success of the tissue-engineered construct[13-15]. An ideal cell delivery vehicle should be able to protect cells from hazards during CPC setting and the injection operation, and is fast degradable to release the viable cells throughout the scaffold after CPC has set. To fabricate such a cell delivery system, natural hydrogel biopolymers, such as alginate, are of great interest, because they can be cross-linked under mild conditions to form highly hydrated gel with good biocompatibility and better 
mechanical properties [16-18]. One major concern is that alginate degrades very slowly and uncontrollably in mammals[19]. The controlled degradability of a biomaterial is often a key factor in cell release and tissue replacement. The degradation rate of alginate can be controlled by manipulating polymer molecular weight by Gamma-irradiation[20], partial oxidation of alginate to make it susceptible to hydrolysis[21], and modification of the composition by adding fast-degradable component such as fibrin[22]. Fibrin is the primary protein component of a blood clot and an important regulator in the wound healing process. It provides binding sites for cell attachment, migration and proliferation[23], and can be degraded by plasmin-mediated fibrinolysis within a few days in vivo[24]. Such fast degradability is undesirable for fibrin to be solely used as a scaffold, but a valuable trait to be used as a component in alginate hydrogel to develop a fast-release cell delivery system.

In the present study, the alginate degradability was modified by partial oxidation and by incorporating fibrin into alginate. Human bone marrow mesenchymal stem cells (hBMSCs) were encapsulated in alginate-fibrin hydrogel microfibers (Alg-Fb MF). These microfibers were used as cell delivery vehicles to protect the encapsulated cells during CPC paste mixing, injection and setting reactions. The novel cell-laden microfiber-CPC construct could be injected or placed into bone defects and harden in situ. Once delivered, these microfibers could degrade inside the scaffold to release cells and subsequently create long macroporous channels in CPC for cell migration, re-organization and tissue ingrowth.

The objectives of this study were to: (1) synthesize a novel cell-encapsulating Alg-Fb MF that could quickly degrade and release the cells; (2) investigate the viability, proliferation and osteogenic differentiation of cells released from microfibers; and (3) develop an 
injectable cell-encapsulating Alg-Fb MF-CPC tissue-engineered construct and investigate its bone regeneration in a rat mandibular bone defect model for the first time. The following hypotheses were tested: (1) Microencapsulation and injection in CPC paste would not harm the encapsulated cells; (2) the encapsulated cells could be quickly released from the microfibers after delivery; (3) hBMSC-encapsulated CPC-MF tissue-engineered construct would display a superior capacity for bone regeneration in vivo, compared to control.

\section{Materials and methods}

\subsection{Cell culture}

hBMSCs were obtained from Lonza (Allendale, $\mathrm{NJ}$ ) and cultured in MSC medium, which consisted of low-glucose Dulbecco's modified eagle medium (DMEM, Gibco, Grand Island, NY) supplemented with $10 \%$ fetal bovine serum (FBS, Invitrogen, Carlsbad, CA), $1 \%$ penicillin/streptomycin, $0.25 \%$ gentamicin and $0.25 \%$ fungizone (Gibco). Routine characterization of hBMSCs was provided by the manufacturer (Lonza). It included characterization for surface markers and functional testing for tri-lineage differentiation. Passage 4 cells were used in the following experiments.

\subsection{Synthesis of cell-encapsulating Alg-Fb MF}

Alginate, a family of natural polysaccharides derived primarily from brown seaweed, could form hydrogel by fast cross-linking with multivalent cations under mild conditions[25]. In the present study, alginate (64\% guluronic acid, MW $=75,000-220,000 \mathrm{~g} / \mathrm{mol}$, ProNova, Oslo, Norway) was oxidized at $7.5 \%$ oxidation to increase its degradability, following 
previous procedures[22]. The oxidized alginate was dissolved in saline at a concentration of 2\%. Fibrinogen from bovine plasma (Sigma, St. Louis, MO) was added to the oxidized alginate solution to achieve a series of concentration of $0.1 \%, 0.4 \%$ and $0.8 \%$ (wt/volumn). hBMSCs were resuspended in the alginate-fibrinogen solution at a density of $1 \times 10^{6}$ cells $/ \mathrm{mL}$. $\mathrm{Alg}-\mathrm{Fb} \mathrm{MF}$ were synthesized by extruding the cell solution into a bath of calcium ions and thrombin. This system consisted of a syringe pump (NE-300, New Era Pump Systems, Farmingdale, NY), a $10 \mathrm{~mL}$ syringe (BD) loaded with cell solution, a $27 \mathrm{G}$ stainless flat-end steel needle (210 $\mu \mathrm{m}$ inner diameter), a laboratory stirrer (Daigger, Vernon Hills, IL) and a glass beaker containing $100 \mathrm{~mL}$ of bath fluid with $100 \mathrm{mmol} / \mathrm{L}$ calcium chloride (Sigma) and $1 \mathrm{NIH}$ units per mL of thrombin (Sigma). The syringe pump was placed vertically and fed the cell solution into the needle tip at a rate of $6 \mathrm{~mL} / \mathrm{min}$. When the alginate-fibrinogen-based cell solution was spayed into the bath fluid, calcium ions caused the alginate to cross-link, while the reaction between fibrinogen and thrombin produced fibrin. This produced hydrogel microfibers which were incubated in the bath for $20 \mathrm{~min}$ for complete gelation. The following fibrinogen concentrations were used in the alginate in order to determine the best cell delivery $\mathrm{Alg}-\mathrm{Fb} \mathrm{MF}$ :

(1) Alginate microfibers without fibrinogen (control group, designated as "Alg- $0 \% \mathrm{Fb} \mathrm{MF}$ ")

(2) Alginate microfibers with $0.1 \%$ fibrinogen (designated as "Alg- $0.1 \% \mathrm{Fb} \mathrm{MF")}$

(3) Alginate microfibers with $0.4 \%$ fibrinogen (designated as "Alg- $0.4 \% \mathrm{Fb} \mathrm{MF}$ ")

(4) Alginate microfibers with $0.8 \%$ fibrinogen (designated as "Alg- $0.8 \% \mathrm{Fb} \mathrm{MF")}$

The diameters of hydrogel fibers were determined by measuring 50 randomly-selected fibers $(n=50)$ using an optical microscope (Eclipse TE-2000S, Nikon, Melville, NY). 


\subsection{Degradation of Alg-Fb MF}

The degradation of Alg-Fb MF was measured by calculating the percentage of dry weight loss of the microfibers with time, following previous studies[26-28]. Briefly, the hydrogel microfibers, fabricated from $1 \mathrm{~mL}$ of the cell solution, were collected in $40 \mu \mathrm{m}$ nylon cell strainers (BD Falcon, Franklin Lakes, NJ) which had been weighed and marked in advance. After washing with $5 \mathrm{~mL}$ of DMEM medium, the cell strainers with collected microfibers were inserted into 6-well plates, and $6 \mathrm{~mL}$ of MSC growth medium was added into each well to immerse the hydrogel microfibers. The 6-well plates with hydrogel microfibers were incubated in a humidified incubator $\left(5 \% \mathrm{CO}_{2}, 37{ }^{\circ} \mathrm{C}\right)$ for 8 days. The cell growth medium was changed every 2 days. Twenty-five wells were prepared for each group, with five wells for each time period $(0,2,4,6$ and 8 days). On the day of harvest, the remaining hydrogel microfibers in the cell strainers were washed with distilled water gently and then moved to a ventilation hood for pre-dry for 6 hours, followed by lyophilization and weighing of the residual weight. To evaluate the degradation of the hydrogel microfiber with time, the percentage of dry weight loss $\left(\mathrm{P}_{\mathrm{DWL}}\right)$ of the microfiber at each time period was calculated as $\mathrm{P}_{\mathrm{DWL}}=\left[\left(\mathrm{W}_{0}-\mathrm{W}_{\mathrm{T}}\right) / \mathrm{W}_{0}\right]$, where $\mathrm{W}_{0}$ is the dry weight of microfiber at $0 \mathrm{~d}, \mathrm{~W}_{\mathrm{T}}$ is the dry weight of microfiber at one of the time periods tested[29].

\subsection{Cell release and proliferation in Alg-Fb MF}

hBMSCs were encapsulated in the aforementioned four groups of Alg-Fb MF. Cell-encapsulating Alg-Fb MF (200 $\mu \mathrm{L})$ was added to each well of 6-well plates with $2 \mathrm{~mL}$ 
MSC growth medium and cultured up to 8 days. Cell medium was changed every 2 days. A total of 24 wells per group were prepared, with six wells culturing for 2, 4, 6 and 8 days.

To examine cell release and viability, the samples were stained with a live-dead kit (Molecular Probes, Eugene, OR) for $30 \mathrm{~min}$, which contained $2 \mu \mathrm{M}$ calcein-AM and $2 \mu \mathrm{M}$ ethidium homodimer-1. The samples were then examined via an epifluorescence microscopy (Eclipse TE-2000S, Nikon, Melville, NY). Live cells were stained green and dead cells were stained red. For quantification of cell viability and proliferation both inside and outside microfibers, a fluorescence microplate protocol was used. Cells were collected from five wells of each group at every time point for cell counting $(n=5)$. To collect both the cells retaining in the un-degraded $\mathrm{Alg}-\mathrm{Fb} \mathrm{MF}$ and those released to the tissue culture polystyrene, a dual-treatment was performed. Two $\mathrm{mL}$ of alginate depolymerization solution $(110 \mathrm{mM}$ sodium citrate, $40 \mathrm{mM}$ EDTA and $150 \mathrm{mM}$ sodium chloride, $\mathrm{pH} 6.8$ in distilled water) was added to each well and incubated for 10 minutes[30]. Then, the dissolved $\mathrm{Alg}-\mathrm{Fb}$ cell suspension was collected to a $50 \mathrm{~mL}$ centrifuge tube. The released cells that were adherent to the tissue culture polystyrene were collected via a regular cell detachment method using $0.25 \%$ trypsin-EDTA (Gibco) for 3-5 minutes. Cell suspension collected from microfibers and tissue culture polystyrene from one well was collected into the same centrifuge tube. The cells were centrifuged to pellet and re-suspended in $1 \mathrm{~mL}$ PBS. Then, $100 \mu \mathrm{L}$ of cell resuspension was added into each well of a 96-well plate and incubated with $100 \mu \mathrm{L} 2 \mathrm{X}$ concentrated Live-Dead staining solution (Molecular Probes, Eugene, OR) for 45 minutes. Three replicates from the same cell suspension were prepared for the measurement. The fluorescence emissions were measured via a microplate reader 
(M5 SpectraMax, Molecular Devices, Sunnyvale, CA) at $530 \mathrm{~nm}$ for the live cells (calcein AM stain) and $645 \mathrm{~nm}$ for the dead cells (ethidium homodimer-1 stain, EthD-1). The live cell number at each time point was calculated via a standard curve made by a series of known live cell numbers. The cell proliferation index (CPI) was calculated by normalizing the cell counts for both the control and experimental groups to the initial numbers, following a previous study[31]. $\quad \mathrm{CPI}=\mathrm{N}_{\mathrm{T}} / \mathrm{N}_{0}$, where $\mathrm{N}_{\mathrm{T}}$ is the live cell number at the tested time, $\mathrm{N}_{0}$ is the average live cell numbers at 0 day.

\subsection{Fabrication of CPC-MF-hBMSC constructs}

CPC powder was prepared following previous studies[32, 33]. Briefly, TTCP [Ca $\left(\mathrm{PO}_{4}\right)_{2} \mathrm{O}$ ] was synthesized using DCPA $\left(\mathrm{CaHPO}_{4}\right)$ and calcium carbonate (both from J.T. Baker, Philipsburg, NJ) which were mixed and heated at $1500{ }^{\circ} \mathrm{C}$ (Model 51333, Lindberg, Watertown, WI). The mixture was ground to obtain TTCP powder with a median particle size of $5 \mu \mathrm{m}$. DCPA was ground to obtain a median particle size of approximately $1 \mu \mathrm{m}$. Then the TTCP and DCPA powders at 1:3 molar ratio were mixed to form the CPC powder[4, 33]. CPC powder was mixed with distilled water at a powder to liquid mass ratio of 2 to 1. The CPC paste was mixed with cell-encapsulating Alg-Fb MF at a volume ratio of 1:1 to form the CPC-MF-hBMSC construct. Based on previous investigation of degradability and cell-releasing capability in Sections 2.3 and 2.4, Alg- $0.4 \% \mathrm{Fb}$ MF was selected for the following in vitro and in vivo studies.

\subsection{Re-collected MF after extrusion}


Immediately following the preparation of CPC-MF-hBMSC paste, the paste was loaded into a $5 \mathrm{~mL}$ syringe with a tip opening of $2.7 \mathrm{~mm}$ for injection. A syringe pump was used to control the extrusion speed at $4 \mathrm{~mL} / \mathrm{min}$. A $100 \mu \mathrm{m}$ nylon cell strainer (BD Falcon, Franklin Lakes, NJ) was used to collect the extruded paste. The CPC paste was washed away by serum-free DMEM medium. The hydrogel microfibers left in the cell strainers after repetitive washing were referred to as the re-collected MFs.

\subsubsection{Cell re-collection percentage}

The re-collected MFs were dissolved in alginate depolymerization solution for 10 minutes. The resulting Alg-Fb cell suspension was centrifuged to obtain the re-collected hBMSCs. These cell samples were re-suspended in PBS for cell counting. The live-dead staining fluorescence microplate protocol was used to calculate the live cell percentage as stated in Section $2.4(n=5)$. The percentage of cell re-collection after extrusion was calculated as $\mathrm{P}_{\mathrm{RE}}=\left(\mathrm{N}_{\mathrm{RE}} / \mathrm{N}_{\text {TOTAL }}\right)$, where $\mathrm{N}_{\mathrm{RE}}$ is the number of re-collected cell after extrusion, $\mathrm{N}_{\text {TOTAL }}$ is the number of cells in $1 \mathrm{~mL}$ cell solution used to produce the hydrogel microfiber.

\subsubsection{Cytokinetic analysis by CCK-8}

To investigate whether the paste mixing and extrusion would harm the encapsulated cells, a cell counting kit (CCK-8, Sigma) was used to evaluate cell viability after extrusion. The re-collected hBMSCs were resuspended at a density of $2 \times 10^{4} / \mathrm{mL} .100 \mu \mathrm{L}$ of cell suspension was added into each well of a 96-well plate and cultured for 8 days. Cytokinetics of the re-collected cells was compared with untreated hBMSCs which were 
seeded at the same density into the 96-well as control. At each time point, $10 \mu \mathrm{L}$ of CCK-8 solution was added to $100 \mu \mathrm{L}$ medium in each well and incubated at $37{ }^{\circ} \mathrm{C}$ for 2 hours. The optical density values (OD value) were measured on a microplate reader (M5 SpectraMax) at a wavelength of $450 \mathrm{~nm}$ and wavelength of $630 \mathrm{~nm}$. The OD of eight consecutive days in each group was plotted to develop the growth curve of the seeded cells $(n=5)[34]$.

\subsubsection{Osteogenic differentiation and mineralization}

Cell-loaded Alg-0.4\%Fb MF was collected after extrusion of CPC-MF-hBMSC construct from the syringe. $100 \mu \mathrm{L}$ recollected MFs, in which $1 \times 10^{5}$ cells were estimated to be encapsulated, was placed into a well of a 24-well plate and cultured for 3 weeks in osteogenic medium (OS), which consisted of MSC growth media plus $100 \mathrm{nM}$ dexamethasone, $10 \mathrm{mM}$ $\beta$-glycerophosphate, $0.05 \mathrm{mM}$ ascorbic acid, and 10nM 1a,25-dihydroxyvitaminD3 (Sigma). Then the mineral deposited by hBMSCs in microfibers was stained with Alizarin Red S (ARS, Millipore, Billerica, MA) following the manufacturer's instruction[32].

\subsection{In vivo mandibular bone defects in rats}

The critical-sized circular defects were created in both sides of the mandibular rami of athymic nude rats (Hsd:RH-Fox1mu, male, 8 weeks old, 200-250 g, Harlan, Indianapolis, IN). The protocol was approved by University of Maryland Baltimore (IACUC \# 0813018), following NIH guidelines. Under general anesthesia $(75 \mathrm{mg} / \mathrm{kg}$ body weight of ketamine and $10 \mathrm{mg} / \mathrm{kg}$ body weight of xylazine), a mucoperiosteal flap was raised at the buccal side of the bone around the mandibular angle. A $5 \mathrm{~mm}$ diameter full-thickness circular defect was 
created at the mandibular ramus under continuous saline irrigation. Cell-encapsulating CPC paste was prepared at the time of implantation. Alg- $0.4 \% \mathrm{Fb} \mathrm{MF}$ was mixed with CPC paste at a volume ratio of 1:1. Six animals with bilateral defects, with a total of 12 defects, were tested. (1) For CPC-MF-hBMSC group $(n=6)$, the cell-encapsulating CPC-MF paste was implanted into one of the two defects in each rat. (2) For CPC-MF-Control (n = 6), CPC-MF paste without cells was implanted into another defect in each rat as a side-by-side control.

\subsection{Histological and histomorphometric analyses}

At 12 weeks after implantation, all animals were euthanized, and the implants embedded in the surrounding native bone were retrieved and fixed in $10 \%$ formalin for 48 hours. Specimens were decalcified and embedded in paraffin. The central part of the implant and defect was cut into $5 \mu \mathrm{m}$ thick sections and stained with hematoxylin and eosin (HE). The slices were scanned using a Scanscope Digital Slide Scanner (Aperio, Vista, CA) and analyzed by Imagescope software (Aperio). New bone area, residual CPC area and total defect area were measured within the boundaries of defects in each section by Image Pro Plus Software (Media Cybernetics, Carlsbad, CA). New bone area fraction was calculated as the new bone area in each defect divided by the total defect area $(n=6)$. Residual CPC area fraction was calculated as the residual CPC area divided by total defect area $(n=6)$.

\subsection{Statistical analyses}

Statistical analyses were performed using Statistical Package for Social Sciences (SPSS 17.0, Chicago, IL). All data were expressed as mean value \pm standard deviation (SD). For 
in vitro results, statistical significance was analyzed using one-way and two-way analyses of variance (ANOVA). A paired-sample $t$ test was used to analyze the data of self-control comparisons for the in vivo results. A confidence level of $95 \%$ was considered significant.

\section{Results}

The alginate hydrogel microfibers were in a long and continuous form. An example of microfiber is shown in Fig. 1A. As the fibrinogen concentration increased from $0.1 \%$ to $0.8 \%$, the mean diameters of the Alg-Fb MFs slightly increased from $251 \pm 25 \mu \mathrm{m}$ to $276 \pm$ $32 \mu \mathrm{m}($ mean $\pm \mathrm{sd}, \mathrm{n}=50)(\mathrm{p}>0.05)$. At $0 \mathrm{~d}$ (immediately after fabrication of cell-encapsulated Alg-Fb MFs), the encapsulated hBMSCs were spherical and distributed throughout the hydrogel microfibers (Fig. 1B). Live cells appeared as green dots, with a few dead cells (red dots) in the microfibers (Fig. 1C).

Controlled degradation is a key requirement for cell delivery vehicles. As illustrated in Fig. 2A, the percentage of dry weight loss $\left(\mathrm{P}_{\mathrm{DWL}}\right)$ increased over time for all $\mathrm{Alg}-\mathrm{Fb} \mathrm{MF}$ groups. At $8 \mathrm{~d}$, Alg- $0 \% \mathrm{Fb}$ MF control exhibited $\leq 20 \%$ dry weight loss, indicating a slow degradation. In contrast, microfibers with fibrin demonstrated a much faster degradation rate. The Alg- $0.4 \% \mathrm{Fb} \mathrm{MF}$ and $\mathrm{Alg}-0.8 \% \mathrm{Fb} \mathrm{MF}$ reached $90 \%$ dry weight loss at $6 \mathrm{~d}$.

Cell viability was not adversely affected by encapsulation, as shown by live/dead staining (Fig. 1 \& 2). At 8 d, Alg-0\%Fb MF still maintained its integrity. Only a few cells demonstrated a spreading morphology, while most cells were in a spherical shape with no evidence of cell releasing from the Alg-0\% Fb MF (Fig. $2 \mathrm{~B}$ and $2 \mathrm{C}$ ). In Alg- $0.1 \% \mathrm{Fb} \mathrm{MF}$ group, cells started to migrate out of the microfibers at $4 \mathrm{~d}$ (Fig. 2D). The released cells 
demonstrated a healthy polygonal morphology as indicated by black arrows in Fig. 2D. At $8 \mathrm{~d}$, more cells were released and robustly proliferated (Fig. 2E). In the Alg-0.4\%Fb MF group, cells were released from the microfibers as early as day 2 (arrowed in Fig. 1D). Interestingly, at day 2 , cells still inside the $\mathrm{Alg}-0.4 \% \mathrm{Fb} \mathrm{MF}$ appeared to be elongated and spindle-like, extending their filopodia and establishing intercellular connections to create a complicated 3 dimensional cellular network (arrowed in Fig. 1E). Alg-0.4\%Fb MF lost its integrity and released most of the encapsulated cells at $4 \mathrm{~d}$ (Fig. 1F). The released hBMSCs attached to tissue culture polystyrene and proliferated rapidly. Fluorescent images showed abundant live cells (green) with a few dead cells (red) at $8 \mathrm{~d}$ (Fig. 1H and 1I). The cells in Alg- $-0.8 \% \mathrm{Fb}$ MF demonstrated similar behavior to that of the Alg- $0.4 \% \mathrm{Fb}$ MF group at day 2, in which cells started to stretch out and a few cells migrated out of the microfibers (Fig. 3A, 3B). However, at day 4, it appeared that cells in $\mathrm{Alg}-0.8 \% \mathrm{Fb}$ MF would rather adhere to each other and assemble to the orientation along the long axis of the microfibers, instead of migrating outside (Fig. 3C, 3D). The contact-inhibition seemly compromised the cell proliferation. Thus till $8 \mathrm{~d}$, cell confluence for Alg- $0.8 \% \mathrm{Fb} \mathrm{MF}$ was not as good as that for Alg- $0.4 \% \mathrm{Fb} \mathrm{MF}$ (Fig. 3E). In addition, more dead cells were observed in Alg- $0.8 \% \mathrm{Fb} \mathrm{MF}$ group than in the other groups (Fig. 3F).

The cell proliferation index (CPI) results are plotted in Fig. 4A. In Alg MF control, the number of hBMSCs appeared to be constant in the first 8 days. With the addition of fibrin, CPI increased over time. In Alg-0.1\%Fb MF group, CPI underwent a slight decrease at $2 \mathrm{~d}$, but then increased to $2.86 \pm 0.16$ at $8 \mathrm{~d}$. Cells in $\mathrm{Alg}-0.4 \% \mathrm{Fb}$ MF group demonstrated the earliest and fastest proliferation. $\mathrm{CPI}$ increased to $1.39 \pm 0.22,2.33 \pm 0.13,3.89 \pm 0.15$, 
$4.35 \pm 0.14$ at 2, 4, 6 and 8 days, respectively, significantly higher than other groups.

In Fig. 4 (B), $\mathrm{P}_{\mathrm{LIVE}}>80 \%$ in the freshly fabricated hydrogel microfibers was achieved in all groups ( $\mathrm{p}>0.05)$. In control, $\mathrm{P}_{\mathrm{LIVE}}$ decreased to $76.2 \pm 4.4 \%$ at $8 \mathrm{~d}$. Alg- $0.1 \% \mathrm{Fb} \mathrm{MF}$ remained a relatively stable level of $\mathrm{P}_{\text {LIVE }}$ over $80 \% . \quad \mathrm{P}_{\text {LIVE }}$ in Alg- $0.4 \% \mathrm{Fb} \mathrm{MF}$ increased to $93.5 \pm 1.8 \%$ at $8 \mathrm{~d}$, which was significantly higher than other groups. In Alg- $0.8 \% \mathrm{Fb} \mathrm{MF}$ group, $\mathrm{P}_{\text {LIVE }}$ declined to $64.3 \pm 4.1 \%$ at $4 \mathrm{~d}$.

Because of its fast-degradability and superior cell-releasing capability, Alg- $0.4 \% \mathrm{Fb} \mathrm{MF}$ was selected for subsequent experiments. The freshly fabricated CPC-MF paste had good flowability and could be completely injected. The percentage of cells re-collected after extrusion $\left(\mathrm{P}_{\mathrm{RE}}\right)$ was as high as $82.3 \pm 4.6 \%$. $\mathrm{P}_{\mathrm{LIVE}}$ of the re-collected cells was $84.9 \pm 2.1 \%$, comparable to that of the freshly fabricated $\mathrm{MF}(85.2 \pm 1.83 \%$, in Fig. $4 \mathrm{~B}, \mathrm{p}>0.05)$. CCK-8 assay showed that the growth of the re-collected hBMSCs was similar to control (Fig. 4C). Representative ARS staining image of mineral synthesis was showed in Fig. 4D. After $14 \mathrm{~d}$ osteogenic induction, the encapsulated hBMSCs formed abundant nodules of mineralization, which was stained red. These results indicate that the microfibers could protect hBMSCs during the CPC mixing and injection processes, and the delivered cells from CPC-MF construct maintained high viability and osteogenic differentiation potential.

Representative histological H\&E images from the animal study are shown in Figs. 5 and 6. In CPC-MF control group (Fig. 5), only a limited amount of new bone was formed at the junction areas between the scaffold and native bone (Fig. 5A and 5B). Infiltration of connective tissue and muscular tissue into the defect was observed (Fig. 5C and 5D). In sharp contrast, samples in the hBMSC-encapsulated CPC-MF group showed nearly complete 
osseous bridge of the defects and much greater amounts of new bone (Fig. 6A and 6B). Higher magnification examination revealed newly-formed trabecular and woven bone with a normal, organized and mature bone morphology in the defects (Fig. 6C and 6D).

As showed in Fig. 7A, the new bone area fraction of CPC-MF-hBMSC group was (42.1 $\pm 7.8) \%$, much higher than $(12.6 \pm 6.7) \%$ of CPC-MF-Control group ( $<$ < 0.05). In Fig. 7B, the residual CPC area fraction of CPC-MF-hBMSC was $(5.8 \pm 1.5) \%$, much less than $(17.3 \pm$ $2.7) \%$ of control $(\mathrm{p}<0.05)$.

\section{Discussion}

In this study, an injectable Alg-Fb MF stem cell delivery system was developed, and a novel tissue engineered construct by dispersing the cell-encapsulating Alg-Fb MF in $\mathrm{CPC}$ for injectable bone tissue engineering was investigated. $\mathrm{Alg}-\mathrm{Fb} \mathrm{MF}$ protected the cells during CPC mixing and injection, and supported the viability, migration and differentiation of encapsulated hBMSCs. By implanting the CPC-MF construct in a mandibular bone defect model, more than 3-fold increase in new bone formation was achieved via the CPC-MF-hBMSCs group, compared to the control without cell delivery.

An efficient cell delivery system is of crucial importance for the success of tissue-engineered constructs[35]. The cell delivery vehicle needs to disperse cells evenly in a three-dimensional scaffold, to protect and maintain cell viability and functionality, and to deliver cells in a timely and controlled manner. Hydrogels, based on both natural and synthetic polymers, have been used for this purpose[17, 36]. Cells are typically encapsulated by gelling cell suspension in a hydrogel solution to form a solidified matrix. A 
frequently-used material is alginate[37-39]. With advantages of mild gelation and easy manipulation, alginate can be produced in various forms, including microbeads[40, 41], microfibers[42,43], and hydrogel blocks[44]. Cell encapsulation in bulk alginate hydrogels offers the simplest encapsulation method. However, due to nutritional deficiency caused by the long diffusion path and accumulation of waste products inside the bulk, such an alginate hydrogel block often undesirably forms a central necrotic core[44]. The use of small microbeads can facilitate the gas, nutrition and waste diffusion, thus promote cell viability and regenerative potential of the constructs. Our previous studies successfully generated an oxidized alginate-fibrin microbead with several hundred microns in size[22]. These microbeads started to degrade at $4 \mathrm{~d}$ and released the encapsulated cells. In the present study, cells were encapsulated in alginate-fibrin hydrogel in the form of microfibers. Encapsulation of cells in microfibers possesses several advantages over microbeads. First, microfibers with tailored lengths and diameters can be fabricated via the simple method of needle extrusion/external gelation. In contrast, in order to break up the alginate droplets to form microbeads in size of several hundred microns, air injection and electronic injection are often required[45]. The air flow or applied electrostatic force during microbead formation may impose harsh shearing forces on the cells. Furthermore, air flow can form "tails" on microbeads which may cause an immune response[45]. Second, microfibers with diameters of several hundred microns and long lengths of millimeters are relatively easy to handle individually. Third, microfibers can provide more space for cellular self-assembly through which living cells may organize into functional units, allowing the cells to grow, migrate and differentiate in the extracellular matrix[46]. Fourth, when mixed together with another 
scaffolding matrix such as CPC, microfibers can form long macroporous channels with excellent interconnectivity upon alginate degradation inside CPC, while microbeads can only form spherical pores with limited interconnectivity. These long macroporous channels could improve osteoconduction by facilitating ingrowth of cells and blood vessels into CPC scaffold.

Alg- $0.4 \% \mathrm{Fb}$ MF not only accelerated the degradation of alginate and thus promoted early cell release, but also markedly promoted cell migration inside microfibers to establish cell-cell interconnection as early as day 2. Initially, cells were suspended within the aqueous environment inside microfibers in all groups. For the Alg MF group, only a few cells appeared to spread inside the microfibers with no cell-cell interconnection at day 8 . The majority of the encapsulated cells exhibited a spherical morphology which indicated an inactive state. The inactive cellular behavior is due to the fact that native alginate does not have receptors for mammalian cell attachment, which makes alginate gels relatively inert[47, 48]. In contrast, in Alg- $0.4 \% \mathrm{Fb} \mathrm{MF}$ group, an extensive cellular network was formed and orientated along the long axis of the microfiber at day 2. This phenomenon indicates that the encapsulated cells were in an active state to self-assemble into functional units, which is important for robust cell proliferation and active involvement in regeneration in vivo. Moreover, such alignment of cells in a tubular network resembles the structures of blood vessels and nerve fibers and thus may be beneficial for vascularization and nerve regeneration. Thereafter, a significant amount of cell proliferation and cell release were observed. Fibrin is a natural component of provisional scaffolds in wound healing. It provides binding sites for cell attachment, migration, and proliferation[26]. Thus, cell 
behavior can be steered by the addition of fibrin into alginate. In the present study, a series of fibrinogen concentrations from $0.1 \%$ to $0.8 \%$ with $1 \mathrm{U}$ per $\mathrm{mL}$ thrombin was added to optimize the biodegradability and cell-releasing capability of Alg-Fb MFs. The 0.4\% fibrinogen achieved the best results in cell spreading, migration, release and proliferation. These results are consistent with previous reports that cell behavior was strongly regulated by the fibrin concentration in hydrogels[49, 50]. A high concentration of fibrinogen such as $5 \%$ resulted in a stiffer, less malleable clot with a long degradation time, which hampered cell proliferation. On the other hand, low fibrinogen concentrations such as $0.5 \%$ significantly promoted cell proliferation[49]. In the present study, because of its fast degradability and favorable cell-releasing properties, the Alg- $0.4 \% \mathrm{Fb} \mathrm{MF}$ group was selected to fabricate the novel cell-loading CPC-MF-hBMSC construct.

After injection, cells recollected from the tissue-engineered construct maintained high viability and osteogenic potential, which could play a key role in bone regeneration. The capability of CPC-MF-hBMSC construct for bone reconstruction in vivo was evaluated in rat mandibular critical-sized defects. Different from the cranial bone defect, the mandibular defect is surrounded by masticatory muscles and is subjected to the muscular forces during the animal's functional movements, such as breathing, chewing, and swallowing. Thus, it is challenging to repair mandibular defects. In the present study, the new bone area fraction of the CPC-MF-hBMSC group was nearly 4-fold that of the control without cell delivery. Compared to our previous in vivo studies of CPC bulk scaffold $[32,51]$ and injectable CPC-alginate microbeads paste[40], CPC-MF-hBMSC of the present study yielded a greater amount of new bone, along with less residual CPC. One reason may be that the 
fast-degradable Alg-Fb MF delivered abundant vital pre-osteoinduced hBMSCs throughout the implanted construct. The contribution of hBMSCs for new bone formation in vivo has been proved in many studies[52-54]. Another reason may be that with the fast-degradation of $\mathrm{Alg}-\mathrm{Fb} \mathrm{MF}$, the long macroporous channels thus formed in $\mathrm{CPC}$ provided interconnected pathways in the CPC-MF-hBMSC group for cell migration, proliferation and organization, and facilitate diffusion of oxygen and nutrient. Further studies are needed to more systematically determine bone regeneration in vivo as a function of time such as 1,3 , and 6 months, and to test the novel injectable CPC-MF-hBMSC construct in larger animals.

\section{Conclusion}

A new injectable CPC-MF-hBMSC construct was demonstrated for the first time to regenerate more than 3 -fold of new bone in vivo than control without cell encapsulation. Cell-encapsulating alginate-fibrin microfibers could quickly degrade and release the cells. A fibrin concentration of $0.4 \%$ in $\mathrm{Alg}-\mathrm{Fb} \mathrm{MF}$ resulted in the greatest enhancement of cell migration, release and proliferation. A large amount of cell-cell contacts were established in $\mathrm{Alg}-0.4 \% \mathrm{Fb} \mathrm{MF}$ as early as day 2. The injectable tissue-engineered construct for bone repair was fabricated by mixing the fast-degradable Alg-Fb MF with $\mathrm{CPC}$ paste. After mixing and injection, the cells re-collected from the construct maintained their viability and osteogenic potential in vitro. The hBMSC-encapsulated CPC-MF tissue-engineered construct in vivo displayed a robust capacity for bone regeneration, achieving complete osseous bridging in critical-sized mandibular defects in rats. The novel tissue-engineered injectable construct with stem cell encapsulation is promising to enhance bone regeneration 
in a wide range of dental, craniofacial and orthopedic applications.

\section{Acknowledgments}

We thank Drs. Laurence C. Chow and Carl G. Simon at the National Institute of Standards and Technology for discussions. This study was supported by NIH R01 DE14190 and R21

DE22625 (HX), National Science Foundation of China NSFC 81401794 (PW), NSFC 31328008 (LZ), Guangdong Science Foundation 2014A030313275 (LZ), and University of Maryland School of Dentistry bridge fund (HX).

\section{Disclosure}

There is no conflict of interest.

\section{References}

[1] M.A. Woodruff, C. Lange, J. Reichert, A. Berner, F. Chen, P. Fratzl, J.-T. Schantz, D.W. Hutmacher, Bone tissue engineering: from bench to bedside, Mater. Today 15 (2012) 430-435.

[2] J. Mao, W. Giannobile, J. Helms, S. Hollister, P. Krebsbach, M. Longaker, S. Shi, Craniofacial tissue engineering by stem cells, J. Dent. Res. 85 (2006) 966-979.

[3] P. Bianco, X. Cao, P.S. Frenette, J.J. Mao, P.G. Robey, P.J. Simmons, C.-Y. Wang, The meaning, the sense and the significance: translating the science of mesenchymal stem cells into medicine, Nat. Med. 19 (2013) 35-42.

[4] U.G. Wegst, H. Bai, E. Saiz, A.P. Tomsia, R.O. Ritchie, Bioinspired structural materials, Nat. Mater. 14 (2015) 23-36.

[5] T.M. Farooque, C.H. Camp, C.K. Tison, G. Kumar, S.H. Parekh, C.G. Simon, Measuring stem cell dimensionality in tissue scaffolds, Biomaterials 35 (2014) 2558-2567.

[6] W.E. Brown, A new calcium phosphate, water-setting cement, Cements. research. progress. DOI (1987) 351-379.

[7] C.D. Friedman, P.D. Costantino, S. Takagi, L.C. Chow, BoneSource ${ }^{\mathrm{TM}}$ hydroxyapatite cement: a novel biomaterial for craniofacial skeletal tissue engineering and reconstruction, J. Biomed. Mater. Res. A 43 (1998) 428-432.

[8] J. Zhang, W. Liu, V. Schnitzler, F. Tancret, J.-M. Bouler, Calcium phosphate cements for bone substitution: chemistry, handling and mechanical properties, Acta Biomater. 10 (2014) 1035-1049.

[9] M.-P. Ginebra, C. Canal, M. Espanol, D. Pastorino, E.B. Montufar, Calcium phosphate cements as drug 
delivery materials, Adv. Drug. Deliver. Rev. 64 (2012) 1090-1110.

[10] L. Chow, Next generation calcium phosphate-based biomaterials, Dent. Mater. J. 28 (2009) 1.

[11] M.D. Weir, H.H. Xu, C.G. Simon, Strong calcium phosphate cement- chitosan- mesh construct containing cell- encapsulating hydrogel beads for bone tissue engineering, J. Biomed. Mater. Res. A 77 (2006) 487-496.

[12] L.M. Grover, A.J. Wright, U. Gbureck, A. Bolarinwa, J. Song, Y. Liu, D.F. Farrar, G. Howling, J. Rose, J.E. Barralet, The effect of amorphous pyrophosphate on calcium phosphate cement resorption and bone generation, Biomaterials 34 (2013) 6631-6637.

[13] D. Mohebbi- Kalhori, M. Rukhlova, A. Ajji, M. Bureau, M.J. Moreno, A novel automated cell- seeding device for tissue engineering of tubular scaffolds: design and functional validation, J. Tissue Eng. Regen. M. 6 (2012) 710-720.

[14] E.M. Bueno, G. Laevsky, G.A. Barabino, Enhancing cell seeding of scaffolds in tissue engineering through manipulation of hydrodynamic parameters, J. Biotechnol. 129 (2007) 516-531.

[15] A. Ouyang, S.T. Yang, Effects of mixing intensity on cell seeding and proliferation in three- dimensional fibrous matrices, Biotechnol. Bioeng. 96 (2007) 371-380.

[16] J.L. Drury, R.G. Dennis, D.J. Mooney, The tensile properties of alginate hydrogels, Biomaterials 25 (2004) 3187-3199.

[17] E. Çelik, C. Bayram, R. Akçapınar, M. Türk, E.B. Denkbaş, The effect of calcium chloride concentration on alginate/Fmoc-diphenylalanine hydrogel networks, Mat. Sci. Eng. C. 66 (2016) 221-229.

[18] J. Yan, Y. Miao, H. Tan, T. Zhou, Z. Ling, Y. Chen, X. Xing, X. Hu, Injectable alginate/hydroxyapatite gel scaffold combined with gelatin microspheres for drug delivery and bone tissue engineering, Mat. Sci. Eng. C. 63 (2016) 274-284.

[19] A.D. Augst, H.J. Kong, D.J. Mooney, Alginate hydrogels as biomaterials, Macromol. Biosci. 6 (2006) 623-633.

[20] E. Alsberg, H. Kong, Y. Hirano, M. Smith, A. Albeiruti, D. Mooney, Regulating bone formation via controlled scaffold degradation, J. Dent. Res. 82 (2003) 903-908.

[21] K.H. Bouhadir, K.Y. Lee, E. Alsberg, K.L. Damm, K.W. Anderson, D.J. Mooney, Degradation of partially oxidized alginate and its potential application for tissue engineering, Biotechnol. Progr. 17 (2001) 945-950.

[22] H. Zhou, H.H. Xu, The fast release of stem cells from alginate-fibrin microbeads in injectable scaffolds for bone tissue engineering, Biomaterials 32 (2011) 7503-7513.

[23] M. Ehrbar, A. Metters, P. Zammaretti, J.A. Hubbell, A.H. Zisch, Endothelial cell proliferation and progenitor maturation by fibrin-bound VEGF variants with differential susceptibilities to local cellular activity, J. Control. Release. 101 (2005) 93-109.

[24] T.A. Ahmed, E.V. Dare, M. Hincke, Fibrin: a versatile scaffold for tissue engineering applications, Tissue. Eng. Part. B. Rev. 14 (2008) 199-215.

[25] S. Koch, C. Schwinger, J. Kressler, C. Heinzen, N. Rainov, Alginate encapsulation of genetically engineered mammalian cells: comparison of production devices, methods and microcapsule characteristics, J. Microencapsul. 20 (2003) 303-316.

[26] J. Brown, C.L. Lu, J. Coburn, D.L. Kaplan, Impact of silk biomaterial structure on proteolysis, Acta Biomater. 11 (2015) 212-221.

[27] J. Huang, D. Zhao, S.J. Dangaria, X. Luan, T.G. Diekwisch, G. Jiang, E. Saiz, G. Liu, A.P. Tomsia, Combinatorial design of hydrolytically degradable, bone-like biocomposites based on PHEMA and hydroxyapatite, Polymer 54 (2013) 909-919.

[28] T. Boontheekul, H.J. Kong, D.J. Mooney, Controlling alginate gel degradation utilizing partial oxidation and bimodal molecular weight distribution, Biomaterials 26 (2005) 2455-2465. 
[29] J.-S. Kim, T.S. Pathak, J.-H. Yun, K.-P. Kim, T.-J. Park, Y. Kim, K.-J. Paeng, Thermal degradation and kinetics of alginate polyurethane hybrid material prepared from alginic acid as a polyol, J. Polym. Environ. 21 (2013) 224-232.

[30] G.J. Van Osch, S.W. Van Der Veen, E.H. Burger, H.L. Verwoerd-Verhoef, Chondrogenic potential of in vitro multiplied rabbit perichondrium cells cultured in alginate beads in defined medium, Tissue Eng. 6 (2000) 321-330.

[31] H. Shin, K. Zygourakis, M.C. Farach-Carson, M.J. Yaszemski, A.G. Mikos, Attachment, proliferation, and migration of marrow stromal osteoblasts cultured on biomimetic hydrogels modified with an osteopontin-derived peptide, Biomaterials 25 (2004) 895-906.

[32] P. Wang, X. Liu, L. Zhao, M.D. Weir, J. Sun, W. Chen, Y. Man, H.H. Xu, Bone tissue engineering via human induced pluripotent, umbilical cord and bone marrow mesenchymal stem cells in rat cranium, Acta Biomater. 18 (2015) 236-248.

[33] W. Chen, W. Thein-Han, M.D. Weir, Q. Chen, H.H. Xu, Prevascularization of biofunctional calcium phosphate cement for dental and craniofacial repairs, Dent. Mater. 30 (2014) 535-544.

[34] L.B. Shi, H.X. Cai, L.K. Chen, Y. Wu, S.A. Zhu, X.N. Gong, Y.X. Xia, H.W. Ouyang, X.H. Zou, Tissue engineered bulking agent with adipose-derived stem cells and silk fibroin microspheres for the treatment of intrinsic urethral sphincter deficiency, Biomaterials 35 (2014) 1519-1530.

[35] R.M. Hernández, G. Orive, A. Murua, J.L. Pedraz, Microcapsules and microcarriers for in situ cell delivery, Adv. Drug. Deliver. Rev. 62 (2010) 711-730.

[36] A.C. Jen, M.C. Wake, A.G. Mikos, Review: Hydrogels for cell immobilization, Biotechnol. Bioeng. 50 (1996) 357-364.

[37] H. Li, F. Jiang, S. Ye, Y. Wu, K. Zhu, D. Wang, Bioactive apatite incorporated alginate microspheres with sustained drug-delivery for bone regeneration application, Mat. Sci. Eng. C. 62 (2016) 779-786.

[38] Y. Zhang, X. Wang, Y. Su, D. Chen, W. Zhong, A doxorubicin delivery system: samarium/mesoporous bioactive glass/alginate composite microspheres, Mat. Sci. Eng. C. 67 (2016) 205-213.

[39] S.M.H. Dabiri, A. Lagazzo, F. Barberis, M. Farokhi, E. Finochio, L. Pastorino, Characterization of alginate-brushite in-situ hydrogel composites, Mat. Sci. Eng. C. 67 (2016) 502-510.

[40] P. Wang, Y. Song, M.D. Weir, J. Sun, L. Zhao, C.G. Simon, H.H. Xu, A self-setting iPSMSC-alginate-calcium phosphate paste for bone tissue engineering, Dent. Mater. 32 (2016) 252-263.

[41] K. Chen, Y. Ling, C. Cao, X. Li, X. Chen, X. Wang, Chitosan derivatives/reduced graphene oxide/alginate beads for small-molecule drug delivery, Mat. Sci. Eng. C. 69 (2016) 1222-1228.

[42] Y. Cheng, F. Zheng, J. Lu, L. Shang, Z. Xie, Y. Zhao, Y. Chen, Z. Gu, Bioinspired multicompartmental microfibers from microfluidics, Adv. Mater. 26 (2014) 5184-5190.

[43] J.M. Yang, J.H. Yang, S.C. Tsou, C.H. Ding, C.C. Hsu, K.C. Yang, C.C. Yang, K.S. Chen, S.W. Chen, J.S. Wang, Cell proliferation on PVA/sodium alginate and PVA/poly ( $\gamma$-glutamic acid) electrospun fiber, Mat. Sci. Eng. C. 66 (2016) 170-177.

[44] E. Hill, T. Boontheekul, D.J. Mooney, Designing scaffolds to enhance transplanted myoblast survival and migration, Tissue Eng. 12 (2006) 1295-1304.

[45] A. Kang, J. Park, J. Ju, G.S. Jeong, S.-H. Lee, Cell encapsulation via microtechnologies, Biomaterials 35 (2014) 2651-2663.

[46] N.A. Raof, M.R. Padgen, A.R. Gracias, M. Bergkvist, Y. Xie, One-dimensional self-assembly of mouse embryonic stem cells using an array of hydrogel microstrands, Biomaterials 32 (2011) 4498-4505.

[47] K. Smetana, Cell biology of hydrogels, Biomaterials 14 (1993) 1046-1050.

[48] J.L. Drury, D.J. Mooney, Hydrogels for tissue engineering: scaffold design variables and applications, 
Biomaterials 24 (2003) 4337-4351.

[49] W. Ho, B. Tawil, J.C. Dunn, B.M. Wu, The behavior of human mesenchymal stem cells in 3D fibrin clots: dependence on fibrinogen concentration and clot structure, Tissue Eng. 12 (2006) 1587-1595.

[50] S. Cox, M. Cole, B. Tawil, Behavior of human dermal fibroblasts in three-dimensional fibrin clots: dependence on fibrinogen and thrombin concentration, Tissue Eng. 10 (2004) 942-954.

[51] X. Liu, P. Wang, W. Chen, M.D. Weir, C. Bao, H.H. Xu, Human embryonic stem cells and macroporous calcium phosphate construct for bone regeneration in cranial defects in rats, Acta Biomater. 10 (2014) 4484-4493. [52] X. Ye, X. Yin, D. Yang, J. Tan, G. Liu, Ectopic bone regeneration by human bone marrow mononucleated cells, undifferentiated and osteogenically differentiated bone marrow mesenchymal stem cells in beta-tricalcium phosphate scaffolds, Tissue Eng. Part C Methods 18 (2012) 545-556.

[53] T. Yoshikawa, H. Ohgushi, K. Ichijima, Y. Takakura, Bone regeneration by grafting of cultured human bone, Tissue Eng. 10 (2004) 688-698.

[54] G. Liu, L. Zhao, L. Cui, W. Liu, Y. Cao, Tissue-engineered bone formation using human bone marrow stromal cells and novel $\beta$-tricalcium phosphateThis work was supported by the National Basic Research Program of China (G1999054300, 2005CB522700) and Shanghai Science and Technology Development Foundation, Biomed. Mater. 2 (2007) 78.

\section{Figure captions}

[1]. The cell encapsulation and release from alginate- $0.4 \%$ fibrin microfiber (Alg- $0.4 \% \mathrm{Fb}$ MF) group: (A) $0 \mathrm{~d}$; (B) $0 \mathrm{~d}$, most of the encapsulated cells were spherical; (C) $0 \mathrm{~d}$, live-dead staining. Arrows indicate that live cells appeared as small green dots in the hydrogel. Dead cells appeared as small red dots. (D) At 2 d, the boundary of microfiber started to become vague with a few cells migrating out (arrowed). (E) At $2 \mathrm{~d}$, live-dead staining showed cell-cell contact inside microfibers (arrowed). (F) At 4 d, microfiber lost its structure. (G) At 8 d, cells grew robustly in and around the microfibers. Fluorescent images $(\mathrm{H})$ and $(\mathrm{I})$ showed abundant live cells (green in $\mathrm{H}$ ) and few dead cells (red in I).

[2]. Degradation of Alg-Fb MFs and cell encapsulation and release from Alg- $0 \% \mathrm{Fb}$ MF and Alg- $0.1 \%$ Fb MF. (A) Percentage of dry weight loss $\left(\mathrm{P}_{\mathrm{DWL}}\right)$ : Each value is the mean of five measurements, with the error bar showing one standard deviation (mean $\pm \mathrm{sd} ; \mathrm{n}=5$ ).

(B) In control group, Alg- $0 \% \mathrm{Fb}$ MF remained its clear boundary at $8 \mathrm{~d}$, with no evidence 
of cell releasing; black arrows indicate that most of cells were spherical while a few cells spread inside the microfibers (red arrows). (C) Fluorescent live/dead image of Alg- $0 \% \mathrm{Fb}$ $\mathrm{MF}$ at $8 \mathrm{~d}$. Arrows indicate cells stretching into a spindle shape. (D) In Alg- $0.1 \% \mathrm{Fb} \mathrm{MF}$, the majority of cells were in spindle morphology at $4 \mathrm{~d}$, and a few cells were released (arrowed). (E) Live/dead staining of Alg-0.1\% Fb MF at $8 \mathrm{~d}$. The number of released cells greatly increased and attached on the tissue culture polystyrene.

[3]. The cell encapsulation and release from $\mathrm{Alg}-0.8 \% \mathrm{Fb} \mathrm{MF}$ group, (A) at $2 \mathrm{~d}$, the boundary of microfiber started to become vague, with some cells migrating out (arrowed). (B) At 2 $\mathrm{d}$, the encapsulated hBMSCs appeared elongated and spindle-like, with filopodia and intercellular connections to create a 3D cellular network. (C) At $4 \mathrm{~d}$, the microfiber lost its integrity but most cells were still inside of the microfiber. (D) At 4 d, live-dead staining. (E) At 8 d, more cells were released. (F) At 8 d, live-dead staining showing dead cells in red.

[4]. Cell proliferation and mineralization. (A) Cell proliferation indexes, and (B) percentage of live cells at 2, 4, 6 and $8 \mathrm{~d}$. (mean $\pm \mathrm{sd} ; \mathrm{n}=5)$. (C) Growth curves of the re-collected cells and the untreated control group. Cell growth was assessed using the CCK-8 cell proliferation assay (mean $\pm \mathrm{sd}$; $\mathrm{n}=5$ ). (D) Abundant small nodules of mineralization synthesized by the released BMSCs from the re-collected MF after $14 \mathrm{~d}$ osteogenic induction were stained red.

[5]. Representative HE images of CPC-MF control group at 12 weeks post-surgery. The decalcified specimens were sectioned along the coronal plane of the central defect area. No bone bridging was achieved in the defect. Only limited new bone was observed in an 
adjacent area of host bon. (C) and (D) were high magnification images within the defects of the dotted-line rectangle areas in (B).

[6]. Representative HE images of the CPC-MF-hBMSC group at 12 weeks post-surgery. Bone bridging was achieved in the critical-sized defects. The defect was closed with newly-formed woven bone and trabecular bone. (C) and (D) were high magnification images within the defects of the dotted-line rectangle areas in (B).

[7]. Quantification of new bone area fraction (A) and residual $\mathrm{CPC}$ area fraction (B). Bars with dissimilar letters indicate significantly different values $(\mathrm{p}<0.05)$. Each value is mean $\pm \operatorname{SD}(n=6)$. 


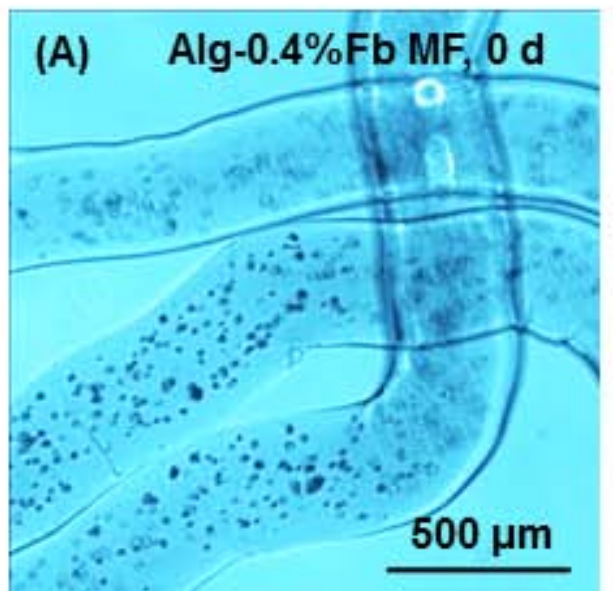

(D) Alg- $0.4 \% \mathrm{Fb} M F, 2 \mathrm{~d}$

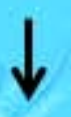

$200 \mu \mathrm{m}$

(G) $\quad$ Alg $-0.4 \% F b$ MF, 8 d

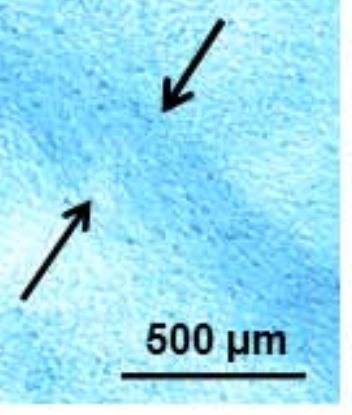

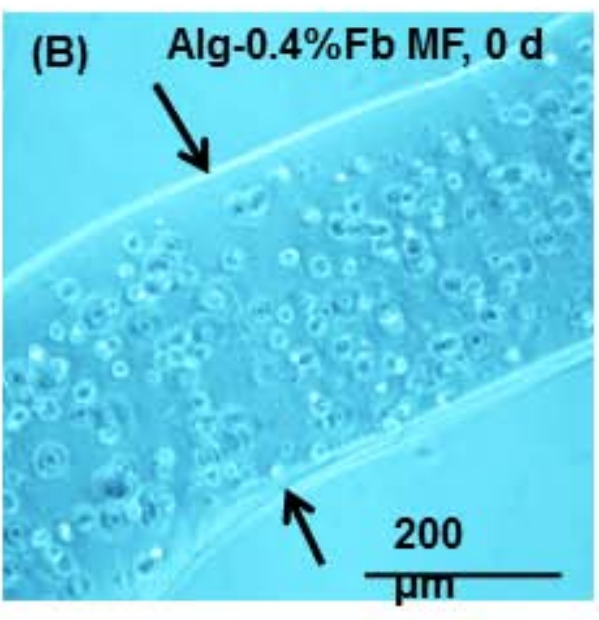

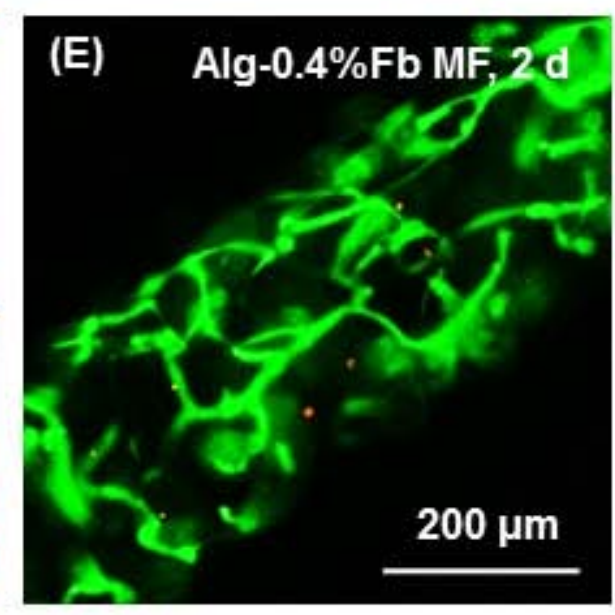

(F) Alg-0.4\%Fb MF, 4 d

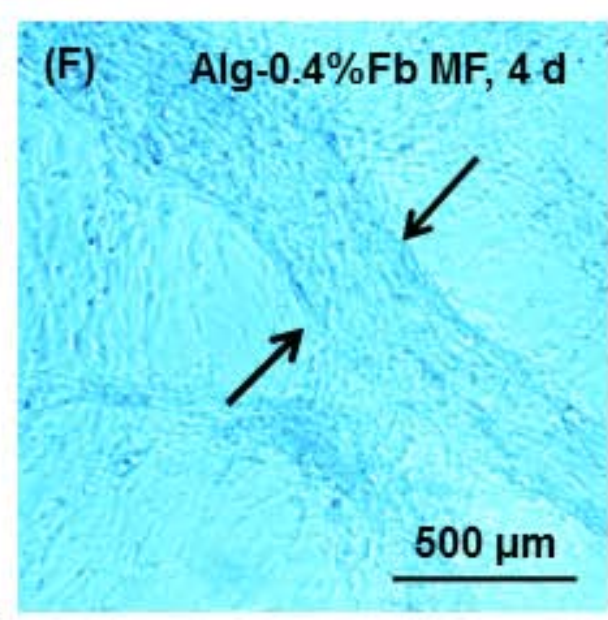

(H) Alg-0.4\%Fb MF, 8 d

(I) Alg-0.4\%Fb MF, 8 d

(C) Alg-0.4\%Fb MF, 0 d
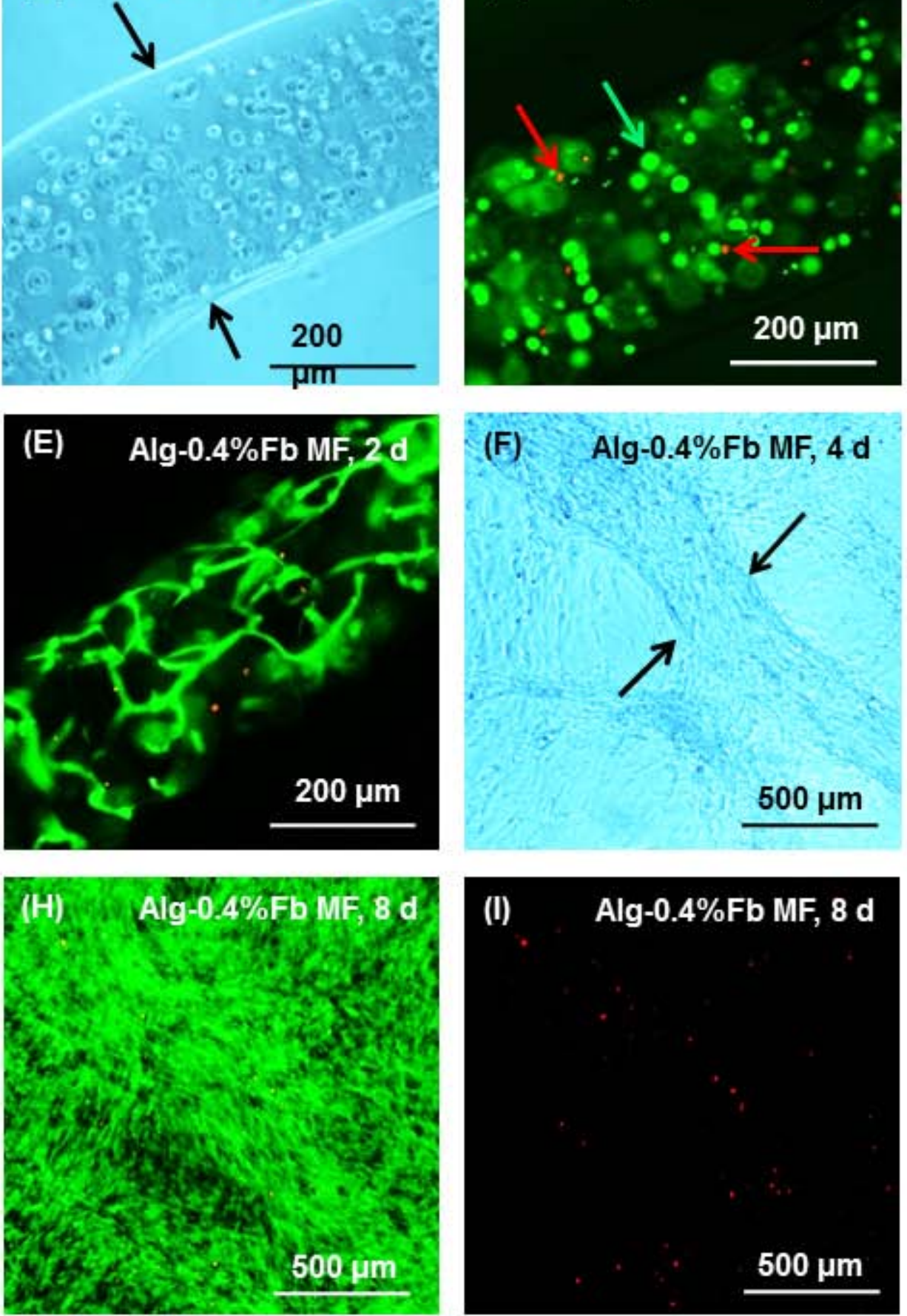

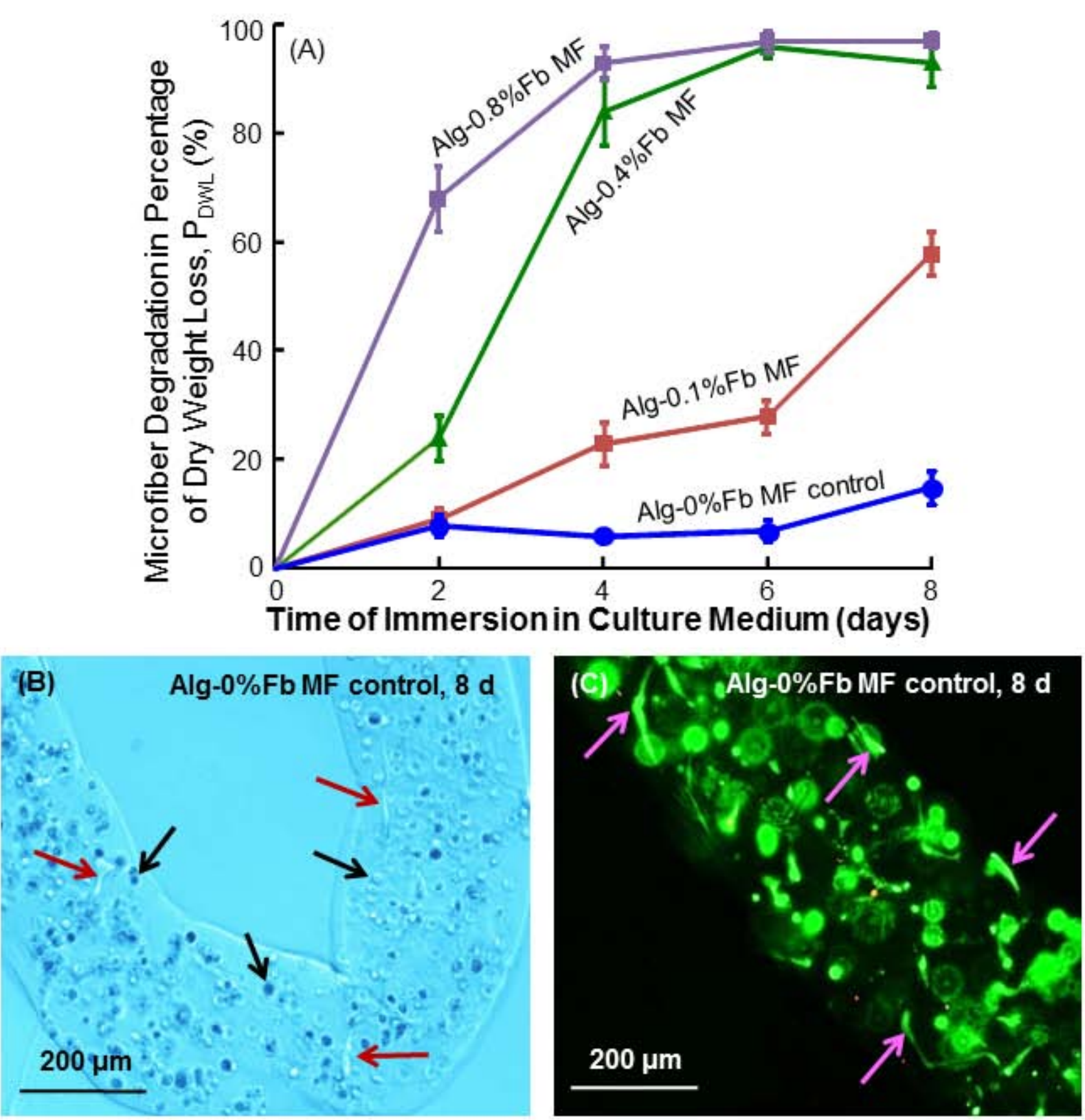

(D)
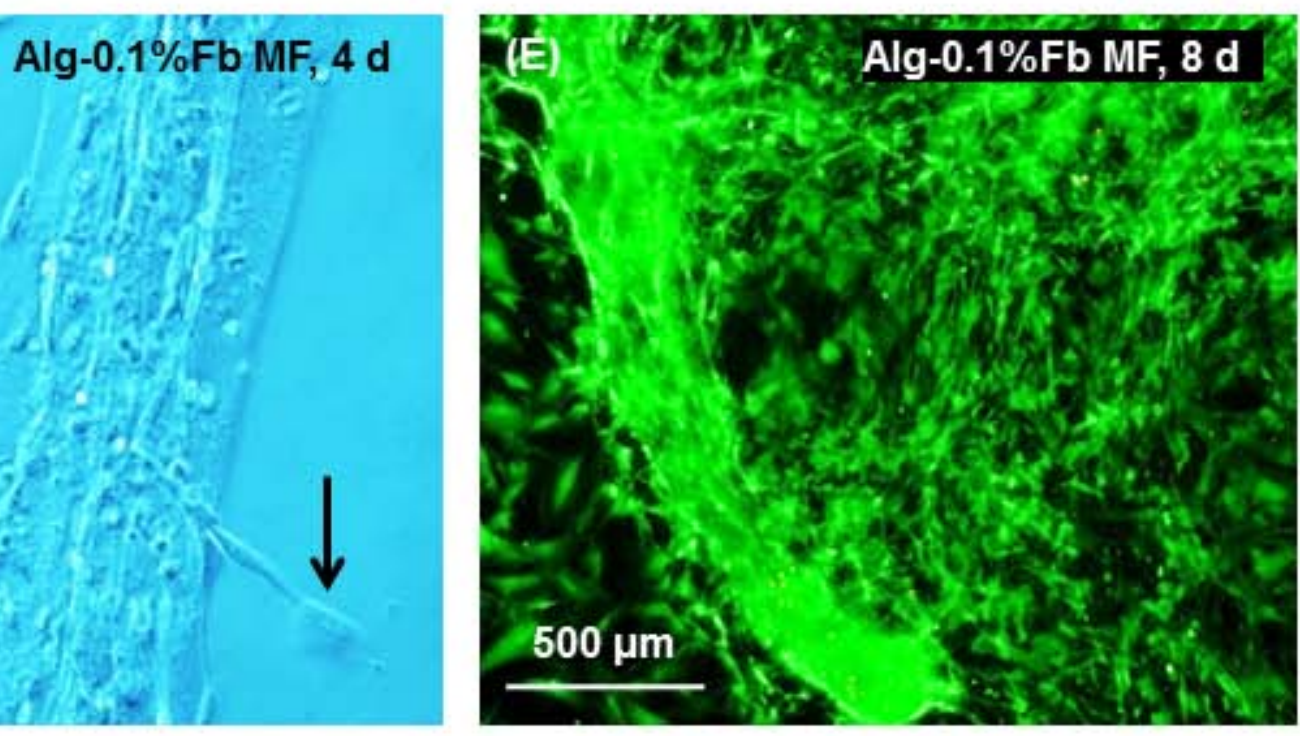

Fig. 2 


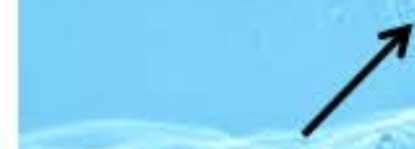

$200 \mu \mathrm{m}$

(C)
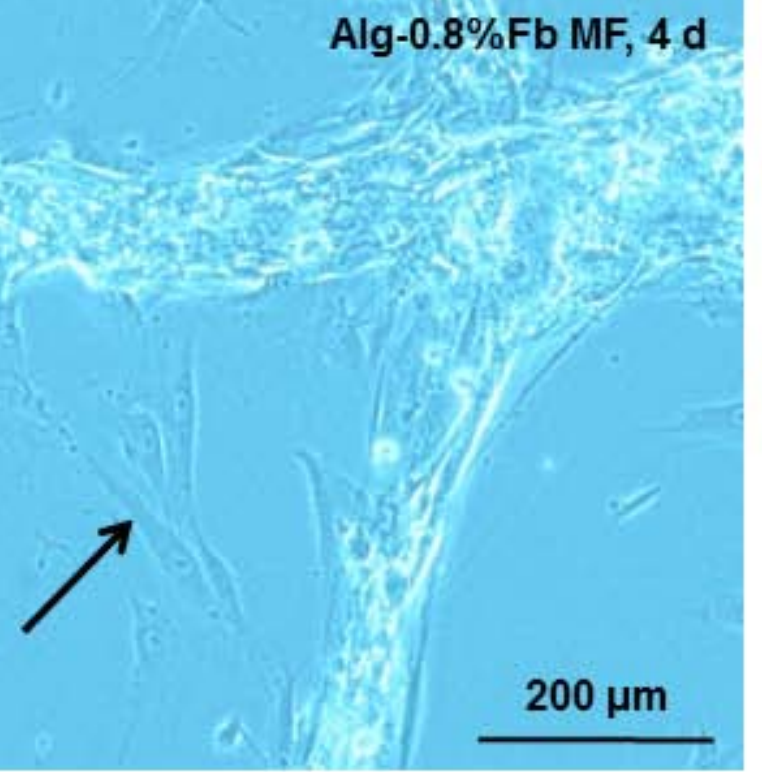

(E) Alg $=0.6 \% \mathrm{Fb} M F, 4 \mathrm{~d}$

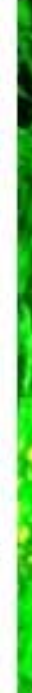
twe
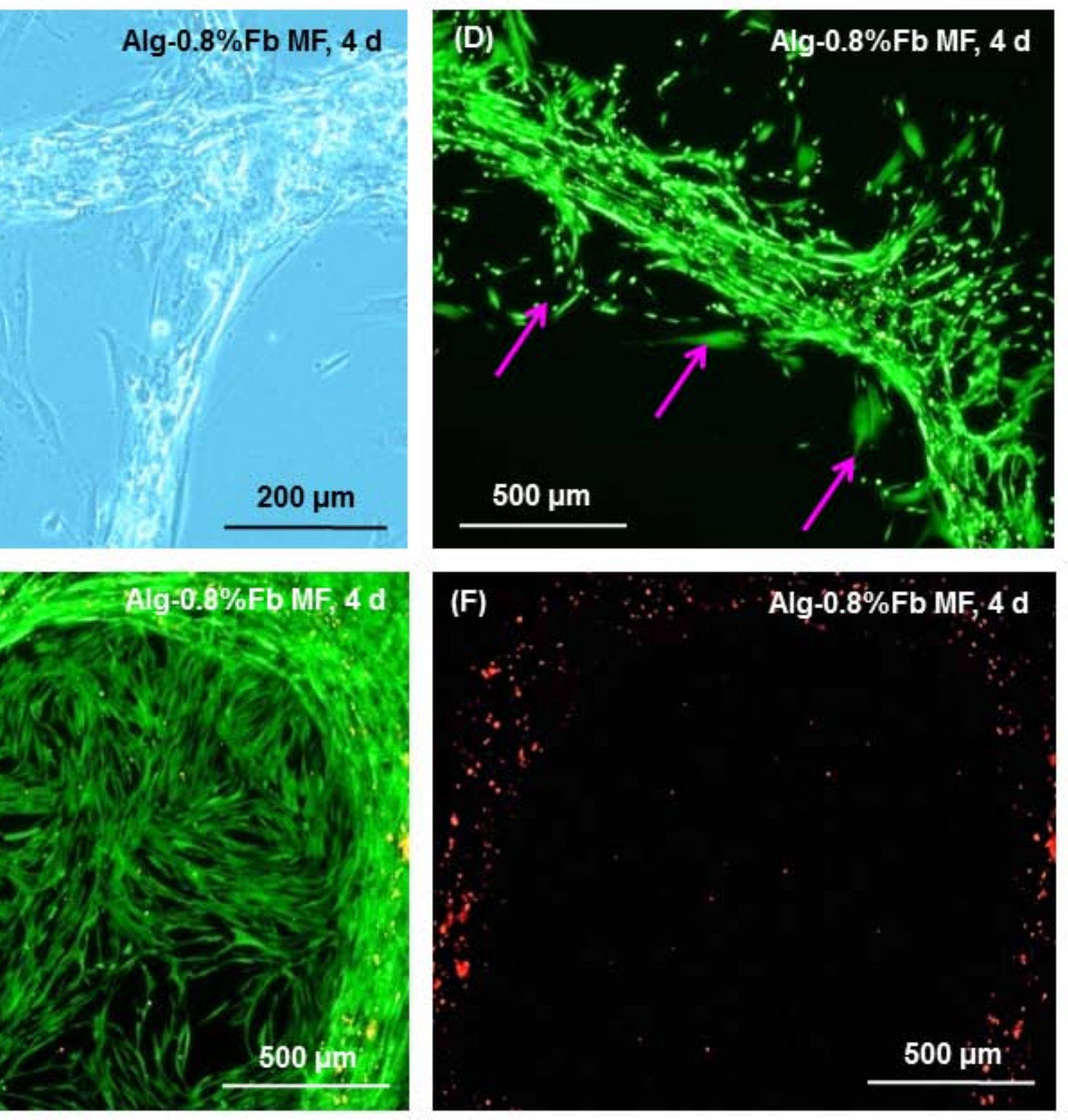

(F) Alg- $0.8 \% F b$ MF, 4 d

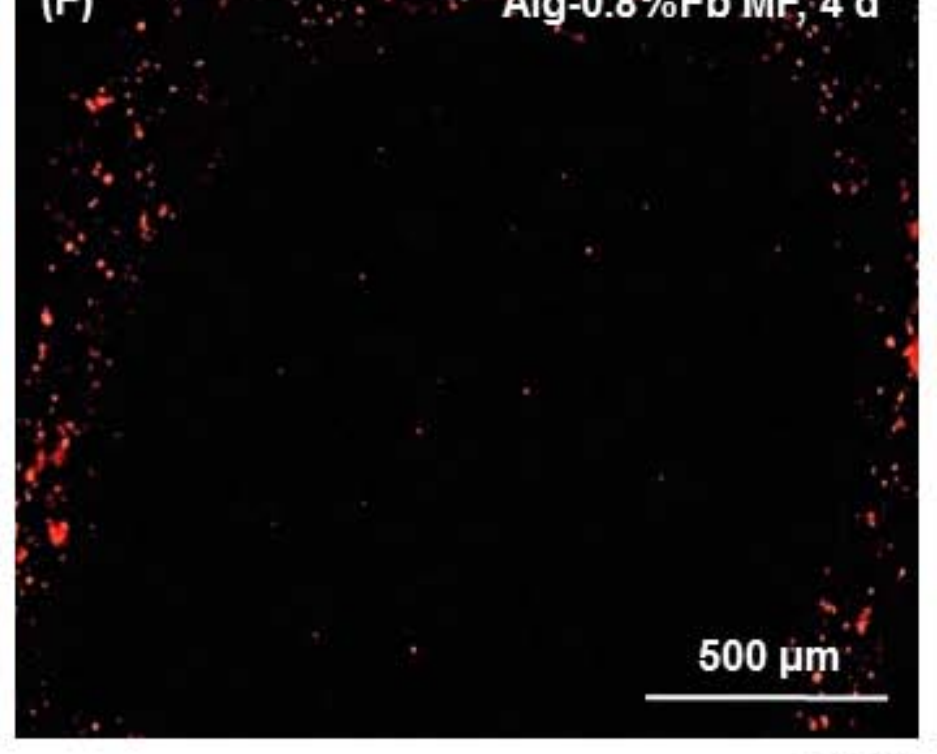

Fig. 3 

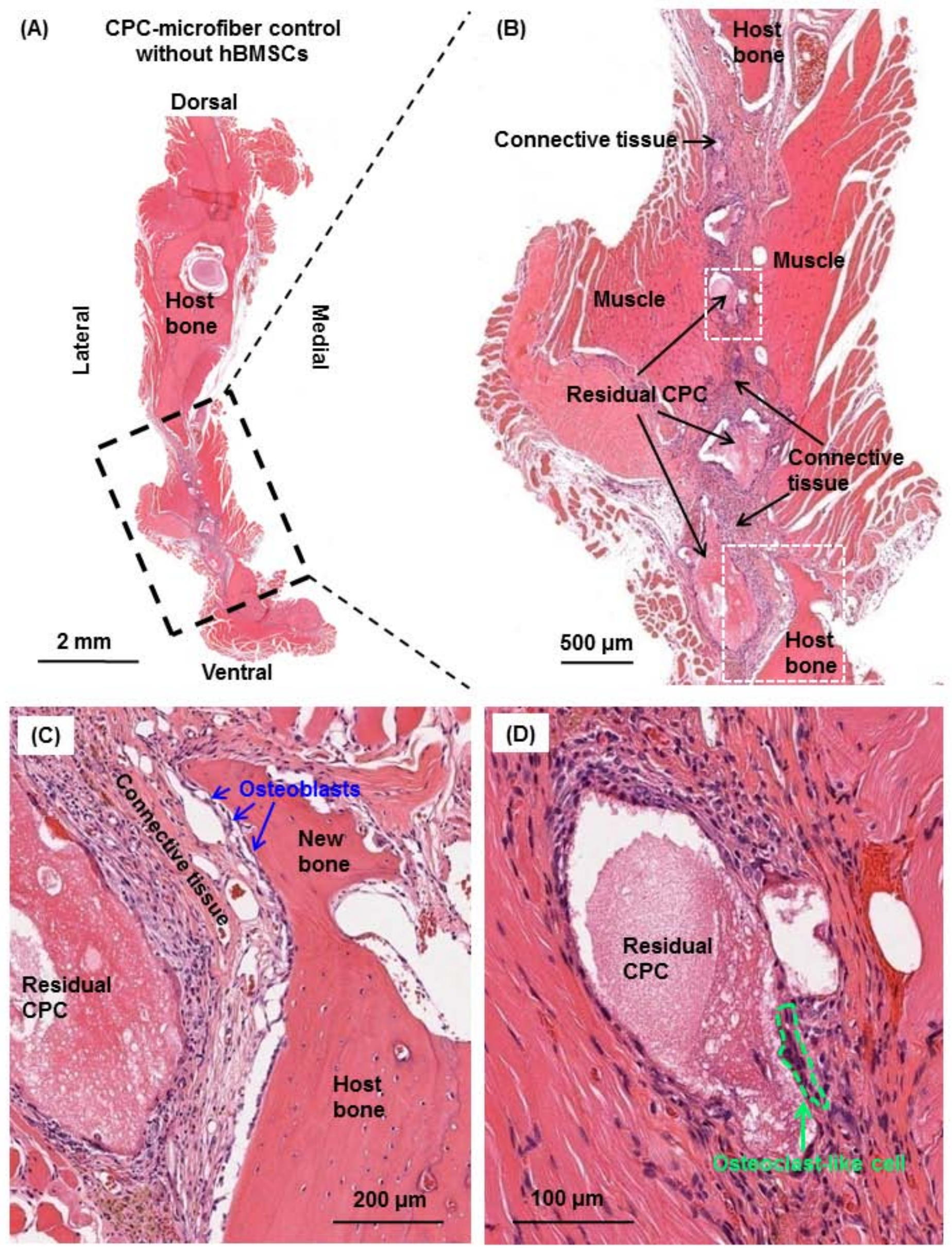

Fig. 5 

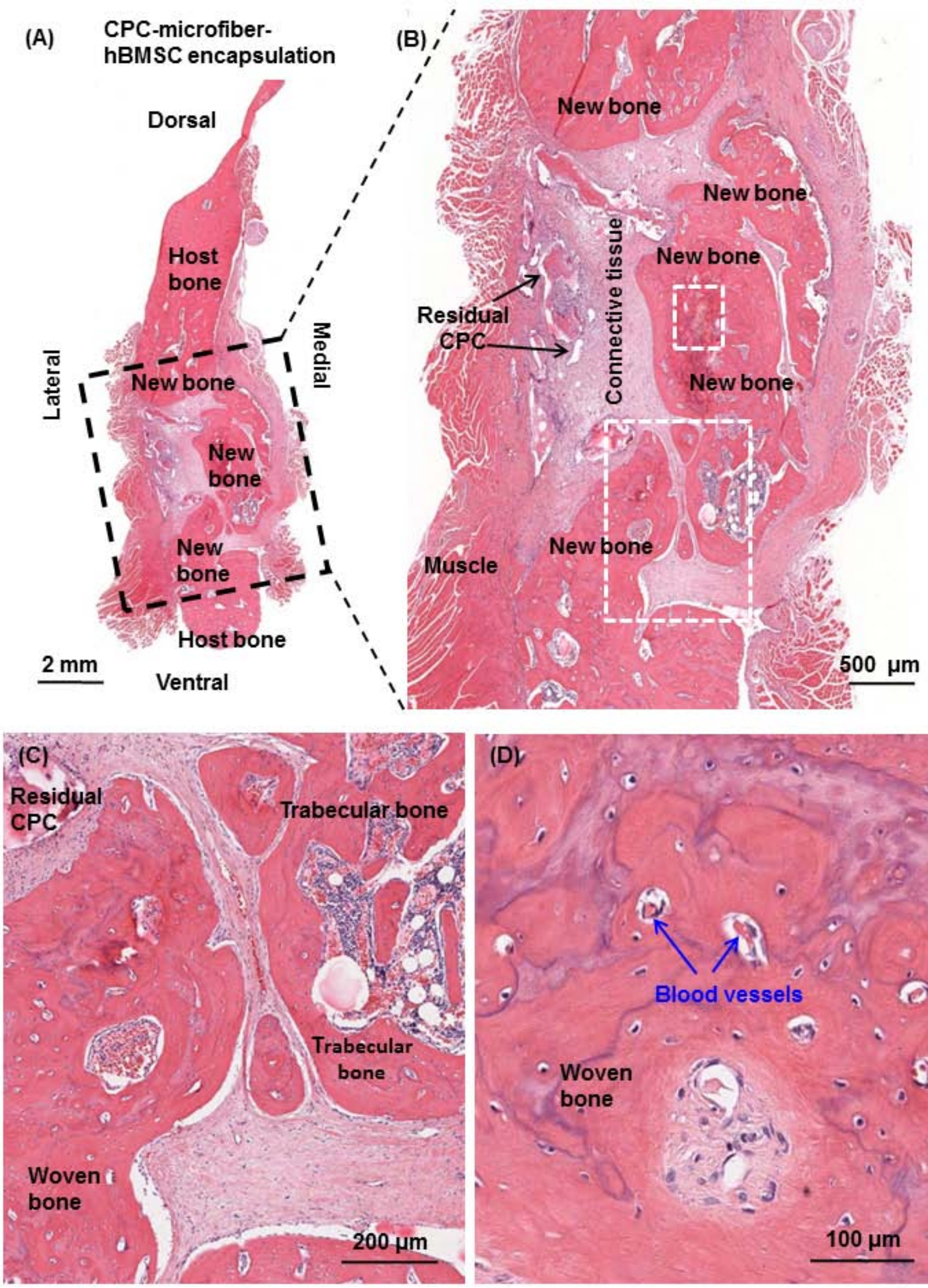

(D)

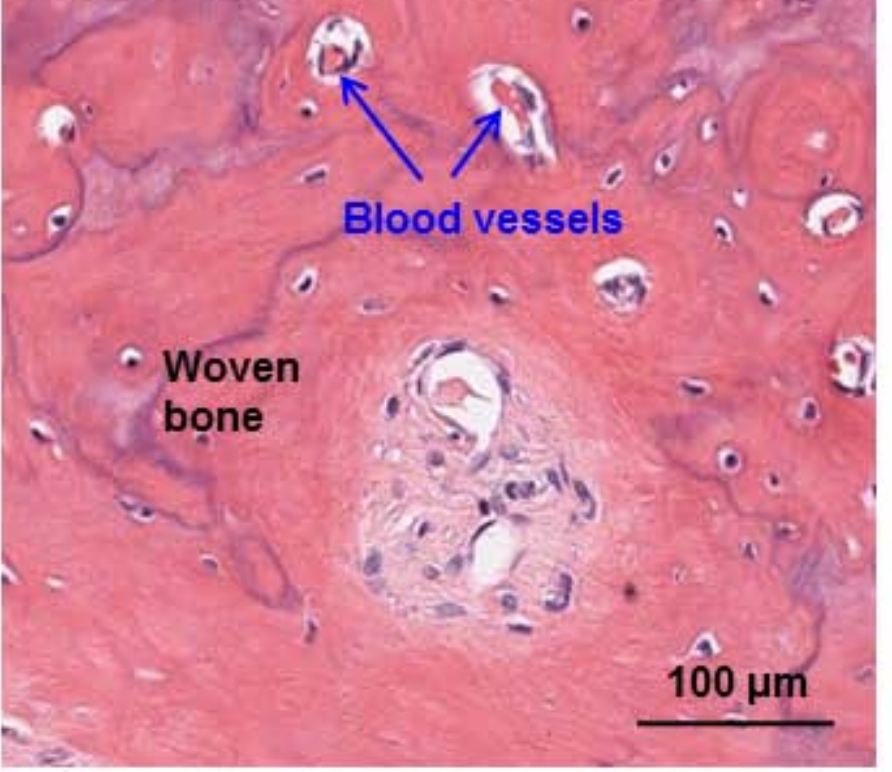



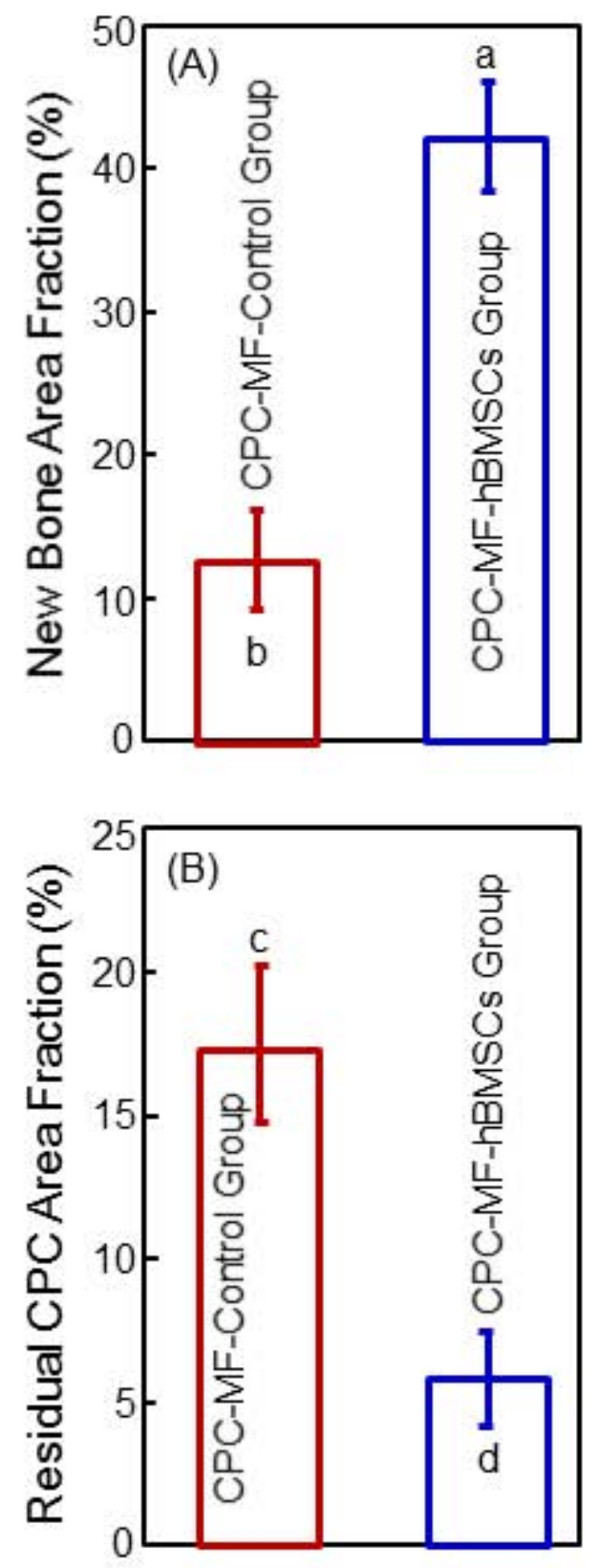

Fig. 7 
Step 1: Cell proliferation

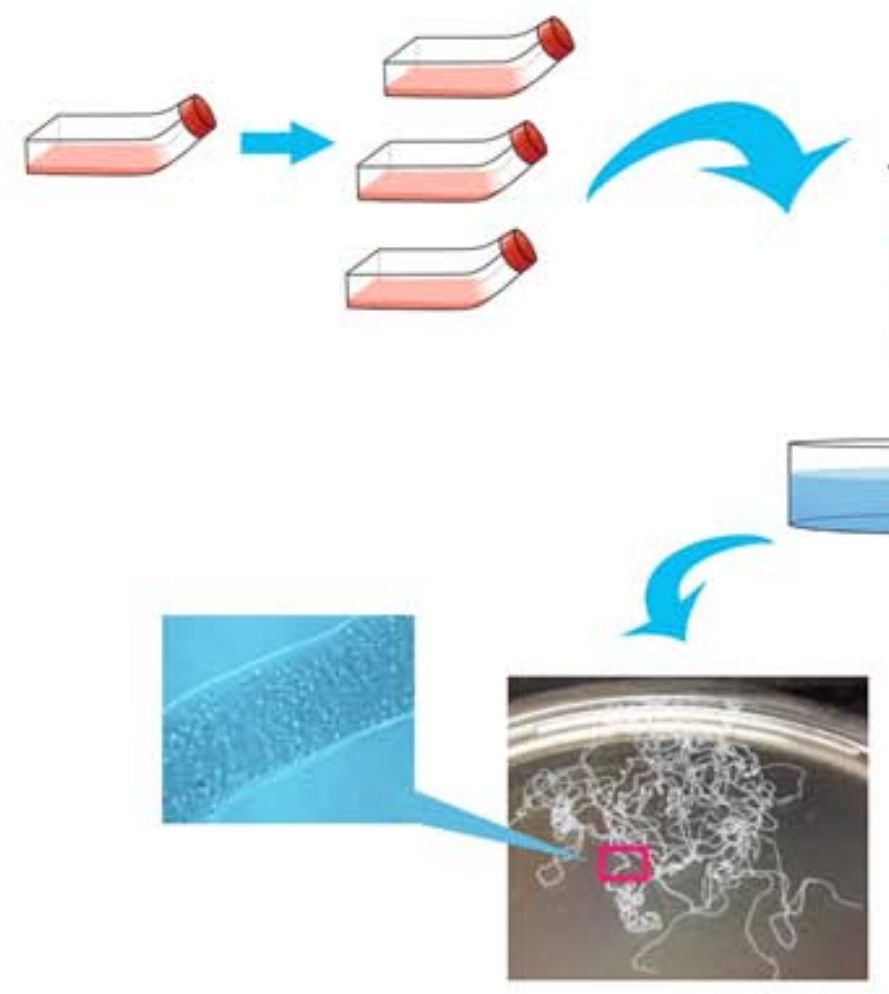

Cell encapsulatedmicrofibers (MF)
Step 2: Microfiberfabrication

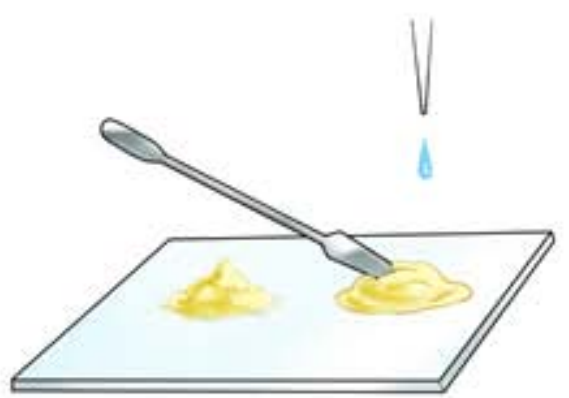

Calcium phosphate cement (CPC)
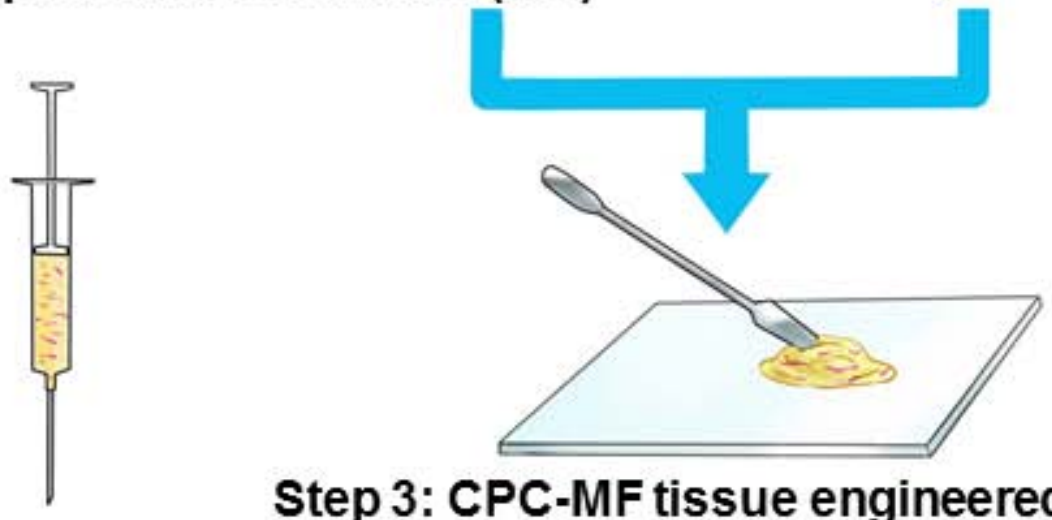

Step 3: CPC-MF tissue engineered construct
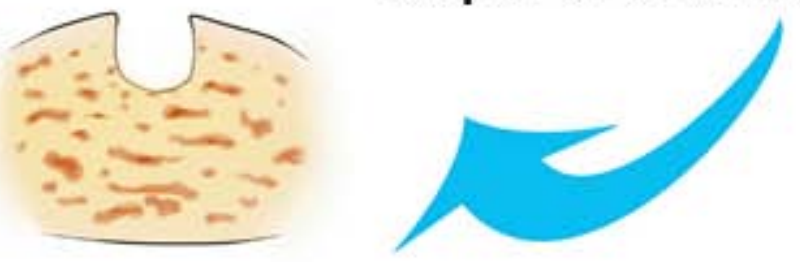

Step 4: Bone defect repair 